\title{
Lens Power in a Population-Based Cross-Sectional Sample of Adults Aged 40 to 64 Years in the Shahroud Eye Study
}

\author{
Rafael Iribarren, ${ }^{1}$ Ian G. Morgan, ${ }^{2}$ Hassan Hashemi,${ }^{3,4}$ Mehdi Khabazkhoob, ${ }^{3}$ \\ Mohammad Hassan Emamian, ${ }^{5}$ Mohammad Shariati, ${ }^{6}$ and Akbar Fotouhi ${ }^{7}$ \\ ${ }^{1}$ Department of Ophthalmology, San Luis Medical Center, Buenos Aires, Argentina \\ ${ }^{2}$ ARC Centre of Excellence in Vision Science, Australian National University, Canberra, Australia \\ ${ }^{3}$ Noor Ophthalmology Research Center, Noor Eye Hospital, Tehran, Iran \\ ${ }^{4}$ Farabi Eye Hospital, Tehran University of Medical Sciences, Tehran, Iran \\ ${ }^{5}$ Shahroud University of Medical Sciences, Shahroud, Iran \\ ${ }^{6}$ Department of Community Medicine, School of Medicine, Tehran University of Medical Sciences, Tehran, Iran \\ ${ }^{7}$ Department of Epidemiology and Biostatistics, School of Public Health, Tehran University of Medical Sciences, Tehran, Iran
}

Correspondence: Akbar Fotouhi, Department of Epidemiology and Biostatistics, School of Public Health, Tehran University of Medical Sciences, Tehran, Iran; afotouhi@tums.ac.ir.

Submitted: November 8, 2013 Accepted: January 17, 2014

Citation: Iribarren R, Morgan IG, Hashemi $\mathrm{H}$, et al. Lens power in a population-based cross-sectional sample of adults aged 40 to 64 years in the Shahroud Eye Study. Invest Ophthalmol Vis Sci. 2014;55:1031-1039. DOI:10.1167/iovs.13-13575
Purpose. To report on calculated lens power in adults in relation to other ocular components of refraction, analyzed in relation to secular change in height and education.

Methods. The first phase of the Shahroud Eye Cohort Study is a cross-sectional populationbased study in Iranian subjects 40 to 64 years old. Data on cycloplegic spherical equivalent refraction and the ocular components of the right eyes were used for the calculation of crystalline lens power with Bennett's formula. Interactions between sex and age as independent variables were analyzed by two-way analysis of variances.

Results. Cycloplegic refraction data and biometry were obtained from 4592 subjects, of whom 2666 (58\%) were women. The mean lens power showed a biphasic trend. Up to the age of 50, younger subjects had lower lens power than older subjects, but after the age of 50, older subjects had lower lens power. A secular trend in height was found, with younger subjects significantly taller than older ones. Taller men or women had longer eyes, with flatter corneas and less powerful lenses, independent of refractive error. In multiple regression models, corneal power $(P<0.001)$, axial length $(P<0.001)$, and lens power $(P<0.001)$ were all associated with height, independent of age and sex.

Conclusions. There was an unexpected biphasic pattern of the distribution of lens power with age in this cross-sectional study. Younger subjects were taller, and despite having longer axial lengths, their bigger eyes were still predominantly emmetropic. The greater axial lengths were counterbalanced by both lower corneal and lower lens powers.

Keywords: lens power, population based study, adult
S pherical equivalent refraction is determined by the com$\checkmark$ bined effect of several ocular components-specifically, axial length, corneal power, anterior chamber depth, and lens power. A large number of population-based studies in older adults have reported on refractive status, although most have not used cycloplegia, which is important for accurate measurement of refraction in children and in young adults. ${ }^{1}$ Several have reported on various aspects of ocular biometry, particularly axial length and corneal power. ${ }^{2-9}$ In contrast, there are very few reports on lens power, because lens power cannot be measured directly but must be calculated from the other parameters. It is important to note that lens thickness, which can be readily measured by biometry, has a complex relationship with lens power and cannot be used as a surrogate measure. Most these studies are purely cross-sectional and thus, considered in isolation, can give, at best, only limited information about possible longitudinal changes.

The paucity of data on lens power is unfortunate, because, compared to other ocular components, lens power is the most changeable throughout life, showing significant changes in both childhood and adult life. While the amount of longitudinal data is very limited, early in development there appears to be a marked loss of lens power, which is rapid in the early childhood years. ${ }^{10}$ This loss slows markedly and progressively to reach a minimal but nevertheless significant rate of loss after the age of 10 to $12,{ }^{11-13}$ and this loss in lens power appears to continue after this age for most of adult life. ${ }^{14}$ Over this period, while the lens slowly loses power, the lens thickens and its curvatures steepen, which should lead to increased power-a phenomenon that has come to be known as the lens paradox. ${ }^{15}$ The observed loss of lens power appears to be due to changes in the gradient index of the lens, ${ }^{16}$ which emphasizes that lens thickness does not provide a surrogate measure of lens power.

In contrast to this lifelong pattern of change in lens power, corneal power stabilizes in the first year or two after birth. ${ }^{17}$ Myopic shifts in refraction continue for much longer, certainly to the end of childhood and even further into the third decade of life, at least in those involved in higher education, ${ }^{18,19}$ probably in association with continuing axial elongation. ${ }^{20-22}$ Early in development, loss of lens power appears to limit the effects of axial growth by balancing the myopic shifts associated with axial elongation against the hyperopic shifts 
Tabie 1. Exclusion Criteria

\begin{tabular}{lr} 
& $\boldsymbol{n}$ \\
\hline Severe pterygium & 96 \\
History of glaucoma surgery & 7 \\
History of retina surgery & 8 \\
History of cataract surgery & 115 \\
History of severe ocular trauma & 21 \\
Missing data of biometry both eye & 74 \\
Nuclear cataract $\geq$ grade 4 & 54 \\
Without lens opacity examination & 106 \\
Without cycloplegic refraction & 102 \\
Missing lens power & 15 \\
Total excluded & 598
\end{tabular}

associated with loss of lens power; but later in adult life, when axial elongation is minimal or has stopped, the slow loss of lens power appears to lead to hyperopic shifts in refraction. ${ }^{14,23}$

The Shahroud Eye Cohort Study is a large, population-based study of adults aged 40 to 64 years at baseline (2009-2010) in Shahroud, a provincial city with a population of over 100,000 in northeastern Iran. It has several strengths, including a large sample size (over 5000); a participation rate of $82.2 \%$; the systematic use of cycloplegia, which is important for the accurate estimation of spherical equivalent refraction and the subsequent calculation of lens power; systematic collection of sociodemographic information; and planned follow-up after 5 years. In this paper, we report on lens power. Longitudinal data from this study are not yet available, but we analyzed the baseline cross-sectional data, taking into account documented patterns of secular change in height and education.

\section{Materials ANd Methods}

The Shahroud Eye Cohort Study is a statistically representative population-based study of 40- to 64-year-old subjects of Shahroud city. Sampling methods are described elsewhere. ${ }^{24}$ All participants received a complete ophthalmic examination, including distance and near uncorrected and best corrected visual acuity, with subjective refractions. Objective refractions were obtained with retinoscopy under cycloplegia (1\% cyclopentolate [Alcon Cusí, Masnou, Spain] was instilled twice, 5 minutes apart, and spherocylindrical refraction was measured after 30 minutes when the pupil was dilated). Corneal radius was measured with an autorefractor (Topcon KR 8800; Topcon Corporation, Tokyo, Japan) and biometry with the Allegro BioGraph (WaveLight AG, Erlangen, Germany). Corneal power was calculated from the corneal radius of curvature assuming a refractive index of 1.3315 as proposed by Olsen. ${ }^{25}$

Lens opacity grading was obtained with slit-lamp biomicroscopy according to the Lens Opacities Classification System III (LOCS III). ${ }^{26}$ Nuclear cataract was defined as nuclear opacities grade 4 and above, ${ }^{26}$ and the diagnosis of cortical and posterior subcapsular cataracts was based on cortical and posterior subcapsular opacities grade 2 and above. Refractive error for a given subject was based on the results of cycloplegic refraction, and spherical equivalent refraction was calculated as the sphere + one-half the cylinder value. Myopia was defined as a spherical equivalent less than -0.5 diopters, and hyperopia was defined as a spherical equivalent greater than +0.5 diopters. As the spherical equivalents of right and left eyes were highly correlated, data are presented for right eyes only. The cycloplegic refractions and the ocular biometry of the right eyes were used for the calculation of crystalline lens power with Bennett's formula. ${ }^{27}$
TABLe 2. Prevalence of Refractive Error ( $\pm 0.50-\mathrm{D}$ Cut Point) by Sex and Age in Years

\begin{tabular}{cccccc}
\hline & Age & $\boldsymbol{n}$ & Myopia & Emmetropia & Hyperopia \\
\hline \multirow{2}{*}{ Female } & $40-44$ & 599 & $23.20 \%$ & $48.10 \%$ & $28.70 \%$ \\
& $45-49$ & 765 & $21.20 \%$ & $52.80 \%$ & $26.00 \%$ \\
& $50-54$ & 648 & $23.10 \%$ & $48.00 \%$ & $28.90 \%$ \\
& $55-59$ & 419 & $19.30 \%$ & $38.70 \%$ & $42.00 \%$ \\
\multirow{4}{*}{ Male } & $60-64$ & 235 & $20.00 \%$ & $30.20 \%$ & $49.80 \%$ \\
& $40-44$ & 292 & $17.80 \%$ & $48.30 \%$ & $33.90 \%$ \\
& $45-49$ & 514 & $23.50 \%$ & $49.80 \%$ & $26.70 \%$ \\
& $50-54$ & 505 & $24.60 \%$ & $53.10 \%$ & $22.40 \%$ \\
& $55-59$ & 391 & $22.50 \%$ & $44.20 \%$ & $33.20 \%$ \\
& $60-64$ & 224 & $19.60 \%$ & $42.00 \%$ & $38.40 \%$ \\
\hline
\end{tabular}

D, diopter.

The prevalence of refractive error was studied across age groups of 5-year intervals from ages 40 to 64 years. As both sex and age can influence refraction and ocular components, the mean values of each dependent variable were studied with two-way ANOVA for sex and age group as independent variables, with post hoc Scheffe tests. Regression models were used to test the associations between the different variables controlled for age and sex. $P$ values were considered significant at the 0.05 level.

The Ethics Committee of Shahroud University of Medical Sciences approved the study protocol, and all participants signed a written informed consent. The study was conducted in accordance with the tenets of the Declaration of Helsinki.

\section{Results}

Of the 5190 subjects aged 40 to 64 years who participated in the study, 598 (11.5\%) were excluded. As nuclear opacity greater than or equal to 4 on the LOCS III scale was associated with increased lens power, subjects with this type of cataract were excluded from the analysis to avoid the known myopic shifts in refraction caused by increased lens power with nuclear cataract. ${ }^{23,28}$ The causes of exclusion are listed in Table 1. The present report is therefore based on cycloplegic refraction data from 4592 subjects, of whom 2666 (58.1\%) were women.

The age and sex distribution is presented in Table 2, where it can be seen that more women in the younger age groups participated. To avoid this imbalance biasing the data, and as sex differences have been often reported in refraction and ocular biometry, as well as in height and education, data were stratified by sex. As also shown in Table 2, the prevalence of myopia ranged between $17 \%$ and $25 \%$ in both men and women, with no clear age-related trends. On the other hand, the prevalence of hyperopia was higher in older subjects (especially in women), while that of emmetropia was lower in older subjects. Consistent with this trend, the mean spherical equivalent was more than +0.45 diopters higher in the older subjects, in both men and women (Table 3, two-way ANOVA for sex and age, $P<0.001)$. Significant changes in axial length and corneal power with age have been previously reported in this sample 29,30 ; but as can be seen in Table 3 , despite the differences in the prevalence of emmetropia and hyperopia, the axial length/corneal radius ratio (AL/CR) did not differ with age (two-way ANOVA for sex and age, $P<0.476$ ).

Surprisingly, the mean lens power showed a biphasic trend, with younger subjects up to the age of 50 having lower lens powers. After that age, older subjects had lower lens power (Fig. 1, two-way ANOVA for sex and age, $P<0.001$ ). Younger 
TABLE 3. Mean Values for the Main Parameters, Data Partitioned by Sex and Age in Years

\begin{tabular}{|c|c|c|c|c|c|}
\hline & \multicolumn{5}{|c|}{ Age Groups, Mean \pm SD } \\
\hline & $40-44$ & $45-49$ & $50-54$ & $55-59$ & $60-64$ \\
\hline \multicolumn{6}{|c|}{ Spherical equivalent, D } \\
\hline Female & $-0.13 \pm 1.67$ & $-0.07 \pm 1.49$ & $-0.19 \pm 2.13$ & $0.21 \pm 2.27$ & $0.37 \pm 1.97$ \\
\hline Male & $-0.13 \pm 2.28$ & $-0.09 \pm 1.29$ & $-0.17 \pm 1.53$ & $-0.01 \pm 1.92$ & $0.31 \pm 1.65$ \\
\hline \multicolumn{6}{|c|}{ Axial length, mm } \\
\hline Female & $23.09 \pm 0.87$ & $22.96 \pm 0.91$ & $22.98 \pm 1.00$ & $22.82 \pm 0.92$ & $22.89 \pm 0.89$ \\
\hline Male & $23.56 \pm 1.08$ & $23.48 \pm 0.90$ & $23.41 \pm 0.87$ & $23.39 \pm 0.96$ & $23.26 \pm 0.93$ \\
\hline \multicolumn{6}{|c|}{ Corneal radius, $\mathrm{mm}$} \\
\hline Female & $7.62 \pm 0.26$ & $7.59 \pm 0.26$ & $7.57 \pm 0.25$ & $7.55 \pm 0.27$ & $7.56 \pm 0.27$ \\
\hline Male & $7.72 \pm 0.27$ & $7.73 \pm 0.27$ & $7.70 \pm 0.26$ & $7.68 \pm 0.28$ & $7.66 \pm 0.29$ \\
\hline \multicolumn{6}{|c|}{$\mathrm{AL} / \mathrm{CR}$ ratio } \\
\hline Female & $3.03 \pm 0.10$ & $3.03 \pm 0.10$ & $3.04 \pm 0.13$ & $3.03 \pm 0.13$ & $3.03 \pm 0.12$ \\
\hline Male & $3.05 \pm 0.14$ & $3.04 \pm 0.10$ & $3.04 \pm 0.11$ & $3.05 \pm 0.12$ & $3.04 \pm 0.11$ \\
\hline \multicolumn{6}{|l|}{ Height, $\mathrm{cm}$} \\
\hline Female & $157.5 \pm 6.11$ & $156.99 \pm 5.54$ & $155.69 \pm 6.98$ & $154.87 \pm 6.71$ & $154.23 \pm 6.50$ \\
\hline Male & $170.15 \pm 7.03$ & $170.17 \pm 6.69$ & $169.29 \pm 6.59$ & $168.14 \pm 7.10$ & $167.32 \pm 6.27$ \\
\hline \multicolumn{6}{|c|}{ Education, $\mathrm{y}$} \\
\hline Female & $6.35 \pm 5.86$ & $6.03 \pm 4.73$ & $5.16 \pm 4.63$ & $4.00 \pm 4.11$ & $2.75 \pm 3.43$ \\
\hline Male & $7.09 \pm 5.25$ & $7.62 \pm 5.36$ & $7.61 \pm 5.33$ & $7.17 \pm 5.47$ & $6.01 \pm 5.05$ \\
\hline
\end{tabular}

women had higher lens power than men, but the two sexes had similar lens power in the older age group (Fig. 1).

To understand this unexpected increasing trend in lens power at younger ages, we looked at possible secular trends in education and height in the population that could influence the ocular components of refraction. Table 3 shows that younger men and women were significantly taller than older men and women (two-way ANOVA for sex and age, $P<0.001$ ), and that younger women were more educated than older ones (two-way ANOVA, $P<0.001$ ). Figures $2 \mathrm{~A}$ and $2 \mathrm{~B}$ show the age differences in axial length and corneal power. It can be seen that younger subjects of both sexes had longer eyes and less powerful, flatter corneas compared to older ones (two-way ANOVA for sex and age, $P<0.001$ both for axial length and for corneal power). This trend was not reflected in the $\mathrm{AL} / \mathrm{CR}$ ratio, which was constant with age (Table 3 ).

One possible explanation for a biphasic pattern of change in lens power could be that younger people, who tended to be taller, had lower lens power than older subjects, who were shorter. This trend could combine with the expected trend for loss of lens power at older ages related to longitudinal hyperopic shifts in refraction. To test this hypothesis, subjects of both sexes were divided into tertiles of height. As can be seen in Figure 3A, the mean spherical equivalent was similar for men and women of different heights (two-way ANOVA, $P=$ 0.182 ). Figures $3 \mathrm{~B}$ through $3 \mathrm{E}$ show the differences in ocular components with height both in men and in women. It can be seen that taller men or women have longer eyes, with flatter corneas and less powerful lenses (two-way ANOVA, $P<0.001$ in all cases). For example, the axial length of males was longer, at $23.72 \mathrm{~mm}$ in the taller males compared to $23.18 \mathrm{~mm}$ in the shorter subjects (equivalent to approximately 1.5 diopters myopic change at the spectacle plane, all other parameters being equal). However, the corneal power was lower, at 42.74 diopters in taller males compared to 43.47 diopters in shorter males, while the lens power was lower in taller males (21.94 compared to 22.61 diopters). Together, these differences in corneal and lens power neutralized the myopic shifts that would otherwise be associated with increased axial length.
Increased anterior chamber depth in taller subjects $(2.73 \mathrm{~mm}$ in taller men compared to $2.62 \mathrm{~mm}$ in shorter men, Fig. 4A) also played a small compensating role. The "anterior segment length" for this study was defined as the distance from the corneal apex to the posterior pole of the lens (per Larsen ${ }^{31}$ ). Figure $4 \mathrm{~B}$ shows the anterior segment length for the different stature tertiles. It can be seen that taller subjects, both men and women, had longer anterior segment lengths.

It is well known that the height of a population decreases longitudinally with age, especially in older subjects. The results of different prospective studies on aging and height were recently reviewed. ${ }^{32}$ As an example, in a Baltimore study, ${ }^{33} 206$ men with a mean age of 45 , followed for a mean of 21 years, had a rate of height loss of $0.063 \mathrm{~cm}$ per year. That would mean that, on average, height would decrease $0.63 \mathrm{~cm}$ every 10 years and $1.26 \mathrm{~cm}$ in 20 years. In the Shahroud population, the 60 -

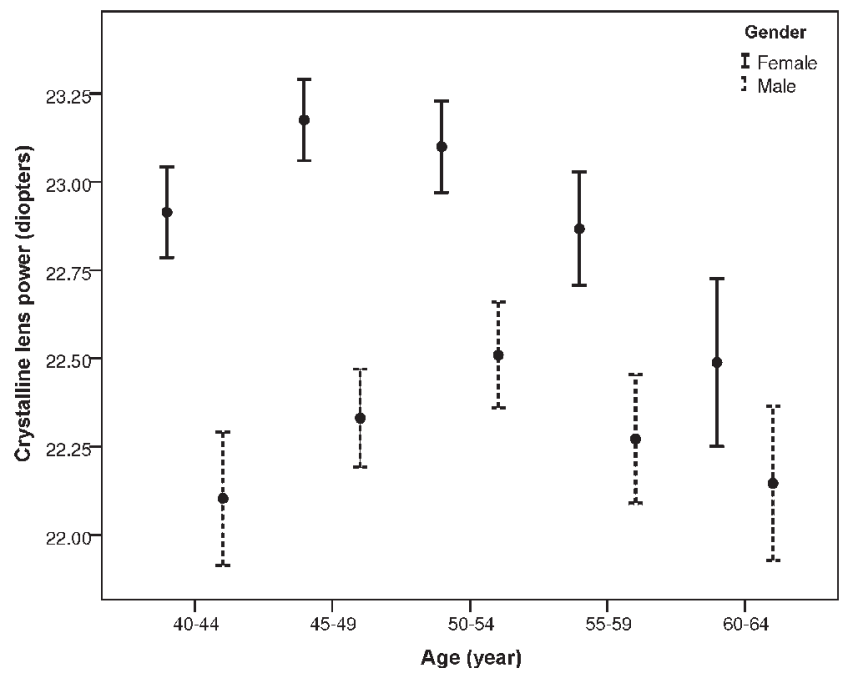

FiguRe 1. Mean lens power for men and women by age groups (error bars represent $95 \%$ confidence intervals). 

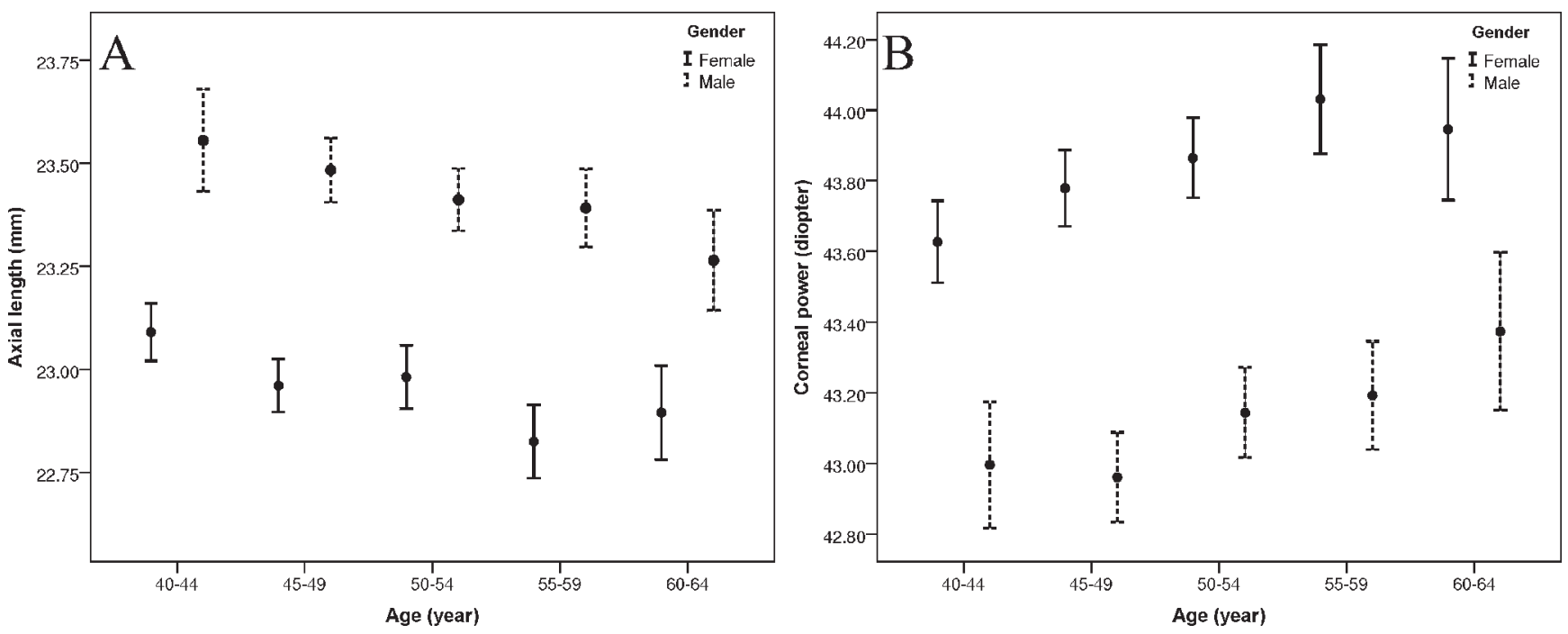

Figure 2. Mean axial length (A) and corneal power (B), partitioned by sex, and plotted against age (error bars represent $95 \%$ confidence intervals).

year-olds were $2.90 \mathrm{~cm}$ shorter than the 40-year-olds, which is a bigger difference than expected from the longitudinal change alone. This greater difference can probably be attributed to secular increases in height. To look at the relationship between height and ocular biometry, multiple regression models were constructed relating height with the ocular parameters adjusted for age and sex. In these models, corneal power $(\beta$ $=-0.599, P<0.001)$ and axial length $(\beta=-0.931, P<0.001)$ were associated with height independently of age and sex. Lens power was also associated with height $(\beta=-0.563, P<$ 0.001 ) adjusted for age and sex in a multiple regression model. Table 4 shows the Pearson correlations between refraction and the ocular components. It can be seen that there are high correlations between refraction and axial length, and between axial length and corneal or lens power.

\section{Discussion}

This study has shown that there is very little difference in refractive error between age groups in this population-based sample of older Iranians, which contrasts with the major differences between age groups that have been reported in East Asian populations. ${ }^{18,34,35}$ In this population, there was an unexpected biphasic pattern of change in lens power in the different age groups, which we suggest can be attributed to differences in height, a product of social changes over the period in which the study population grew up.

It is widely understood that patterns of longitudinal change cannot be derived from cross-sectional data alone because of the potential confounding of longitudinal changes and cohort effects. This greatly limits the conclusions that can be drawn from most population-based epidemiological studies, which is unfortunate because the majority of the data available are cross-sectional, and this is likely to continue to be the case. However, in the absence of cohort effects, the pattern of crosssectional differences with age should simply reflect the pattern of longitudinal change. Therefore, with some information about general longitudinal changes with age, and with information about relevant secular changes in the population, it may be possible to make sense of the cross-sectional patterns observed.

There is some information in the case of refractive error and ocular biometry. The available evidence suggests that corneal power and diameter are remarkably stable from the age of 2 to
3 years until well into adult life. ${ }^{17,36-40}$ Axial length increases at least for the first two decades of life, and this may continue into the third decade in some situations. Since changes in corneal radius and axial length are minimal after the age of 30 , the $\mathrm{AL} / \mathrm{CR}$ ratio is likely to be stable beyond this age. In addition, despite the absence of direct evidence, it is generally accepted that there are longitudinal hyperopic shifts in refraction due to slow loss of lens power for much of adult life, ${ }^{17,23}$ until marked myopic shifts in refraction occur in association with the formation of nuclear cataracts. ${ }^{28,41-43}$

In relation to secular changes, there has been an increase in height in many, if not most, populations over the last century or so, and particularly in the last few decades, as standards of nutrition have improved. ${ }^{44-48}$ In general, increased height is associated with longer axial lengths and flatter corneas. ${ }^{8,49-55}$ This association appears to start in newborn infants, since heavier babies have longer axial lengths and flatter corneasan association that continues during subsequent development in the childhood years. ${ }^{56-59}$ In parallel, increased height primarily involves accelerated growth in the first 2 years of life. ${ }^{44,45}$ However, increased height and longer axial length, on its own, did not lead to more myopic refractions in this study, probably because emmetropization matches axial length to the refractive power of the cornea and lens early in development. Consistent with this idea, while there have been sporadic reports of a relationship between greater height and more myopic refraction, ${ }^{51,60}$ many other studies have reported that there is no relationship. ${ }^{50,52,53,58,61-64}$ Interestingly, the largest report on Israeli army conscripts ${ }^{65}$ reported an inverse relationship (lesser height associated with more myopia), which may suggest that the relationship is social rather than biological, perhaps related to diet and/or study habits.

Many studies have reported a cross-sectional association of education and myopia. ${ }^{8}$ The rapid increase in the prevalence of myopia over the past 50 years in some East and Southeast Asian countries has generally been attributed to the development of mass, highly competitive and intense education systems, with increased axial elongation and myopia in better-educated people. In these countries, the two secular changes have occurred in parallel, leading to a combination of flatter corneas, excessively elongated axial lengths, increased AL/CR ratios, and more myopic refractions.

In many respects, this population of Iranian adults from Shahroud represents a contrasting pattern, with the prevalence of myopia greater than -0.50 diopters stable with age and sex 

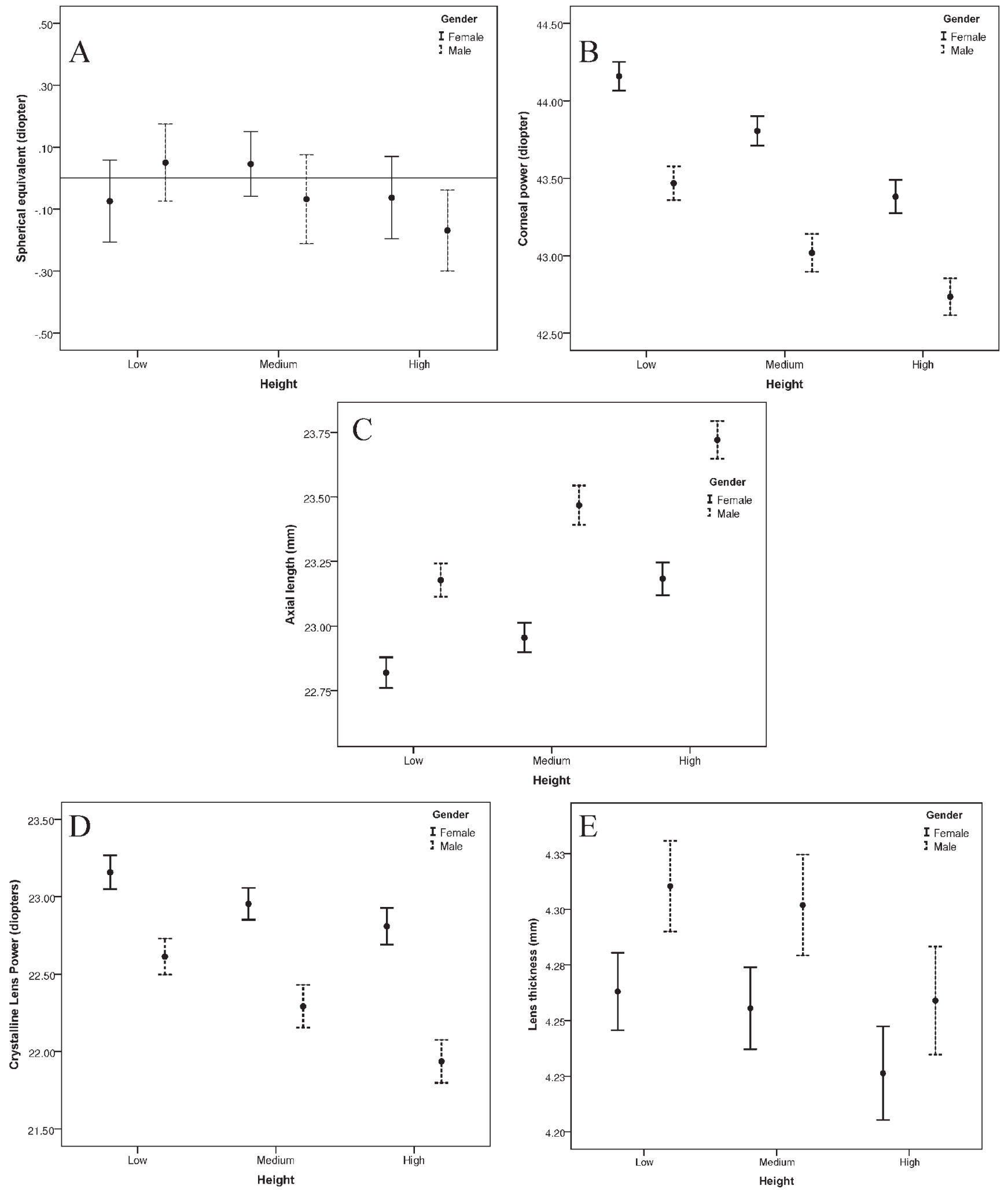

Figure 3. Mean spherical equivalent (A), mean corneal power (B), mean axial length (C), mean lens power (D), and mean lens thickness (E) partitioned by height (tertiles) and sex (error bars represent $95 \%$ confidence intervals).

at around $20 \%$, despite the fact that the younger adults were taller and had longer axial lengths. There was, however, some reduction in the prevalence of emmetropia and an increase in the prevalence of hyperopia in older adults, probably indicative of longitudinal hyperopic shifts in refraction produced by loss of lens power. The increased axial length was associated with greater height in the younger (middleaged) adults, and greater height was also associated with flatter 

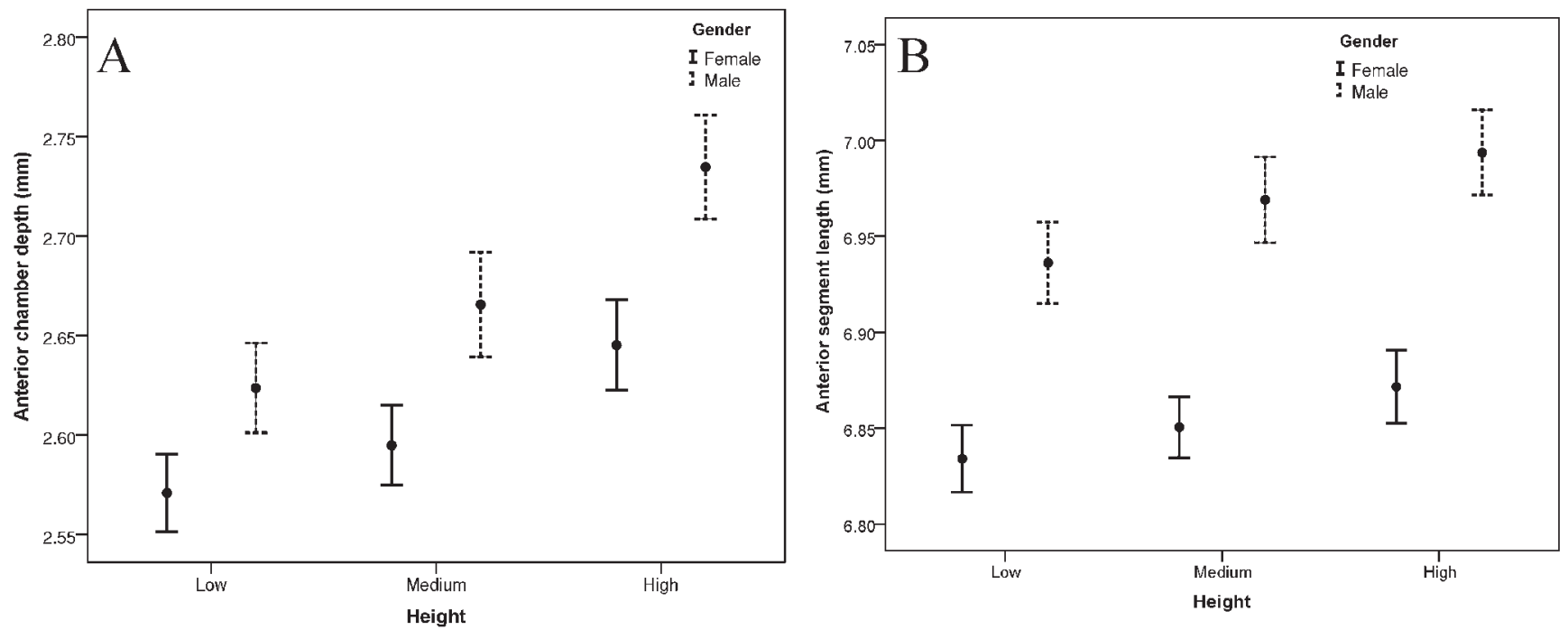

FiguRE 4. Mean anterior chamber depth (A) and mean anterior segment length (B) partitioned by height (tertiles) and sex (error bars represent $95 \%$ confidence intervals).

corneas, which resulted in $\mathrm{AL} / \mathrm{CR}$ ratios that were stable with age. In contrast to expectation, lens power did not decrease monotonically with age, but was particularly low in the youngest age group. The lower power of the lens in larger eyes of younger people would also help to neutralize the impact of the increased axial length on refraction, as could be also the case for a posterior location of the lens in taller subjects (with bigger anterior segment lengths in this study).

Consistent with these patterns, there was a slight increase in height in the younger age groups of this population, in both men and women, which appears to be associated with increased axial lengths, flatter corneas, and less powerful lenses. There was a slight increase in education with age, particularly in women, but in no case did the mean level of education go significantly beyond the primary school years. In other studies, there is some evidence that a threshold level of education, beyond the primary school years, has to be achieved to significantly increase the prevalence of myopia. For example, in Singapore, the prevalence of myopia, estimated from visual acuity measurements, was low for those with only primary school education, but began to increase with different levels of high school and further education. ${ }^{18}$ Similarly, in the Refractive Error Study in Children in rural Nepal, where school enrolment rates are low and where most children do not go beyond primary school, there was no increase in the prevalence of myopia with age. ${ }^{66}$ The adults in the present study had average education to the end of primary school, and although the years of education had increased significantly for women, this might have been insufficient to result in any appreciable increase in the prevalence of myopia.

The results of this study can be usefully compared with other studies, in particular the Tanjong Pagar Study. ${ }^{50}$ In that study, there was a markedly higher prevalence of myopia in the youngest cohort, even before older subjects with nuclear cataract were omitted. Younger subjects were taller and better educated, and there was a clear association between increased education and a more myopic refraction, but there was no relationship between increased height and refraction.

To our knowledge, this is the first report showing that younger, taller generations have eyes with longer axial lengths, longer anterior segments, flatter corneas, and lower-powered lenses, irrespective of refractive error. We have calculated lens powers from published data for three other population-based studies; as can be seen in Table 5, lens power was again lower in those who were taller or had higher birth weights.

These findings in different studies pose the question of how the eye manages to adapt lens power to partially compensate for axial diameter. The lens has an internal power given by the progressive increase in refractive index from the surface to the center that can account for half of its power. The growing aging lens naturally loses power by a progressive steepening of this gradient of refractive index. ${ }^{67}$ Lens growth in animal models is sensitive to humoral factors present in the adjacent peripheral retina and the vitreous ${ }^{68}$; and perhaps the rate of growth could alter the lens gradient of refractive index (a lens that grows at a slow rate would tend to steepen its gradient, and interestingly, taller subjects in this study had thinner

TABLE 4. Correlation Coefficients Between Ocular Components Based on Data From All Subjects Aged 40 to 64 Years, $n=4592, r$ Values

\begin{tabular}{|c|c|c|c|c|c|c|c|}
\hline & Corneal Power & Axial Length & Lens Power & Lens Thickness & ACD & ASL & Height \\
\hline Spherical equivalent, D & $-0.143^{*}$ & $-0.611^{*}$ & +0.004 & $+0.173^{*}$ & $-0.302^{*}$ & $-0.273^{*}$ & -0.021 \\
\hline Corneal power, D & - & $-0.531^{*}$ & $+0.147^{*}$ & -0.018 & +0.011 & +0.003 & $-0.316^{*}$ \\
\hline Axial length, mm & - & - & $-0.552^{*}$ & $-0.234^{*}$ & $+0.492^{*}$ & $+0.469^{*}$ & $+0.323^{*}$ \\
\hline Lens power, D & - & - & - & $+0.323^{*}$ & $-0.446^{*}$ & $-0.373^{*}$ & $-0.238^{*}$ \\
\hline Lens thickness, mm & - & - & - & - & $-0.582^{*}$ & $-0.160^{*}$ & +0.007 \\
\hline $\mathrm{ACD}, \mathrm{mm}$ & - & - & - & - & - & $+0.896^{*}$ & $+0.17^{*}$ \\
\hline ASL, $\mathrm{mm}$ & - & - & - & - & - & - & $+0.212^{*}$ \\
\hline
\end{tabular}

$\mathrm{ACD}$, anterior chamber depth; ASL, anterior segment length

* Correlation is significant at the 0.01 level (two tailed). 
TABLE 5. Comparison of Mean Refractions and Ocular Component Dimensions Summarized From Three Different Published Studies

\begin{tabular}{|c|c|c|c|c|c|c|c|}
\hline & SER, D & $\mathbf{C R}, \mathbf{m m}$ & $\mathbf{A C D}, \mathbf{m m}$ & $\mathbf{L T}, \mathbf{m m}$ & AL, $\mathbf{m m}$ & LP, $\mathbf{D}$ & $\mathbf{A L} / \mathbf{C R}$ \\
\hline \multicolumn{8}{|l|}{ Height, m } \\
\hline \multicolumn{8}{|c|}{ Height and ocular components in adults, Wong et al. ${ }^{50}$} \\
\hline $1.37-1.50$ & -0.24 & 7.55 & 2.7 & 4.92 & 22.74 & 25.68 & 3.01 \\
\hline $1.51-1.55$ & -0.6 & 7.57 & 2.86 & 4.78 & 23.05 & 25.11 & 3.04 \\
\hline $1.56-1.59$ & -0.49 & 7.66 & 2.83 & 4.78 & 23.19 & 25.01 & 3.03 \\
\hline $1.60-1.65$ & -0.6 & 7.68 & 2.99 & 4.68 & 23.44 & 24.44 & 3.05 \\
\hline $1.66-1.83$ & -0.52 & 7.79 & 3.1 & 4.63 & 23.78 & 23.94 & 3.05 \\
\hline \multicolumn{8}{|c|}{ Height and ocular components in adults, Wu et al. ${ }^{53}$} \\
\hline $1.30-1.48$ & -1.53 & 7.53 & 2.7 & 4.47 & 22.36 & 28.35 & 2.97 \\
\hline $1.49-1.54$ & -1.67 & 7.61 & 2.75 & 4.48 & 22.51 & 28.67 & 2.96 \\
\hline $1.55-1.60$ & -1.12 & 7.68 & 2.87 & 4.44 & 22.76 & 27.56 & 2.96 \\
\hline $1.61-1.80$ & -1.4 & 7.76 & 2.87 & 4.48 & 23.14 & 26.96 & 2.98 \\
\hline \multicolumn{8}{|l|}{ Birth weight, kg } \\
\hline \multicolumn{8}{|c|}{ Birth weight and ocular components, Saw et al. ${ }^{57}$} \\
\hline $2.5-2.9$ & -0.35 & 7.69 & 3.58 & 3.5 & 23.13 & 25.04 & 3.01 \\
\hline $3.0-3.4$ & -0.52 & 7.76 & 3.61 & 3.48 & 23.44 & 24.54 & 3.02 \\
\hline $3.5-3.9$ & -0.67 & 7.82 & 3.64 & 3.46 & 23.67 & 24.30 & 3.03 \\
\hline
\end{tabular}

SER, spherical equivalent refraction; CR, corneal radius; LT, lens thickness; AL, axial length; LP, lens power.

lenses). There may be a possible relation between lens power loss and axial length growth in the sense that they could be mutually coordinated during the growth period, as has been previously discussed when a greater rate of lens power loss was found in children at the time of axial myopia development. ${ }^{13}$

The lens as a whole has a limited capacity for loss of power, given the fact that once the superficial layers are compacted and the gradient of refractive index reaches its maximum steepness, no further loss can be accomplished. Subjects with shorter eyes, who have higher lens power to begin with (shallower gradient), could be prone to greater amounts of loss. Perhaps the fact that women have shorter eyes with steeper corneas and more powerful lenses ${ }^{23}$ makes them more prone to having hyperopic shifts by loss of lens power with aging. This is consistent with the fact that women have a greater prevalence of hyperopia with aging and with the fact that at older ages, when the lens power is decreased, they end up with lens power similar to that of men, as if this was the lower mean lens power that could be achieved with aging (Fig. 1).

Finally, in Shahroud, the lens power was lower in the younger, taller generations and also lower in the older subjects. This last change is probably due to hyperopic changes driven by lens power loss in older subjects. Evidence of this is the increasing prevalence of cycloplegic hyperopia in men and women from age 50 to 65 years in this study. Hyperopia in adults has been shown to be related to decreased lens power. ${ }^{23}$ The trend for increased lens power in the smaller eyes of the shorter older generations in this study is probably cancelled by the loss of lens power with aging, resulting in a biphasic pattern of lens power change with age.

These observations have an important clinical implication. Significant changes in height have been observed in most populations in recent years; and there have also been significant, and sometimes rapid, changes in education. This means that population norms for refraction and ocular biometry established on older people may no longer be valid for younger people; and where there have been rapid changes in height and education, population norms for screening and clinical use may need to be updated regularly.

In conclusion, we have found that the bigger eyes in the younger age groups in this study are still emmetropic but have greater axial lengths, with lower corneal and lens powers and bigger anterior segment lengths. In the absence of other secular changes that affect eye growth, such as increases in educational standards, early emmetropization and loss of lens power seem to minimize the effect of changes in height and ocular biometry on refraction. It will be interesting to see how these parameters change in the younger generations in Iran, where educational and nutritional standards have continued to improve.

\section{Acknowledgments}

Supported by Noor Ophthalmology Research Center and Shahroud University of Medical Sciences. The authors alone are responsible for the content and writing of the paper.

Disclosure: R. Iribarren, None; I.G. Morgan, None; H. Hashemi, None; M. Khabazkhoob, None; M.H. Emamian, None; M. Shariati, None; A. Fotouhi, None

\section{References}

1. Fotouhi A, Morgan IG, Iribarren R, Khabazkhoob M, Hashemi $\mathrm{H}$. Validity of noncycloplegic refraction in the assessment of refractive errors: the Tehran Eye Study. Acta Opbthalmol. 2012;90:380-386.

2. Wong TY, Foster PJ, Ng TP, Tielsch JM, Johnson GJ, Seah SK. Variations in ocular biometry in an adult Chinese population in Singapore: the Tanjong Pagar Survey. Invest Ophthalmol Vis Sci. 2001;42:73-80.

3. Shufelt C, Fraser-Bell S, Ying-Lai M, Torres M, Varma R; Los Angeles Latino Eye Study Group. Refractive error, ocular biometry, and lens opalescence in an adult population: the Los Angeles Latino Eye Study. Invest Ophthalmol Vis Sci. 2005;46: 4450-4460.

4. Warrier S, Wu HM, Newland HS, et al. Ocular biometry and determinants of refractive error in rural Myanmar: the Meiktila Eye Study. Br J Opbthalmol. 2008;92:1591-1594.

5. Fotedar R, Mitchell P, Burlutsky G, Wang JJ. Relationship of 10year change in refraction to nuclear cataract and axial length findings from an older population. Opbthalmology. 2008;115: 1273-1278, 1278.e1.

6. Olsen T, Arnarsson A, Sasaki H, Sasaki K, Jonasson F. On the ocular refractive components: the Reykjavik Eye Study. Acta Ophthalmol Scand. 2007;85:361-366. 
7. Nangia V, Jonas JB, Sinha A, Matin A, Kulkarni M, Panda-Jonas S. Ocular axial length and its associations in an adult population of central rural India: the Central India Eye and Medical Study. Ophthalmology. 2010;117:1360-1366.

8. Eysteinsson T, Jonasson F, Arnarsson A, Sasaki H, Sasaki K. Relationships between ocular dimensions and adult stature among participants in the Reykjavik Eye Study. Acta Opbthalmol Scand. 2005;83:734-738.

9. Wickremasinghe S, Foster PJ, Uranchimeg D, et al. Ocular biometry and refraction in Mongolian adults. Invest Ophthalmol Vis Sci. 2004;45:776-783.

10. Mutti DO, Mitchell GL, Jones LA, et al. Axial growth and changes in lenticular and corneal power during emmetropization in infants. Invest Ophthalmol Vis Sci. 2005;46:30743080 .

11. Jones LA, Mitchell GL, Mutti DO, Hayes JR, Moeschberger ML, Zadnik K. Comparison of ocular component growth curves among refractive error groups in children. Invest Ophthalmol Vis Sci. 2005;46:2317-2327.

12. Twelker JD, Mitchell GL, Messer DH, et al. Children's ocular components and age, gender, and ethnicity. Optom Vis Sci. 2009;86:918-935.

13. Iribarren R, Morgan I, Chan Y, Lin X, Saw S. Changes in lens power in Singapore Chinese children during refractive development. Invest Ophthalmol Vis Sci. 2012;53:5124-5130.

14. Hashemi H, Iribarren $R$, Morgan IG, Khabazkhoob M, Mohammad K, Fotouhi A. Increased hyperopia with ageing based on cycloplegic refractions in adults: the Tehran Eye Study. Br J Ophthalmol. 2010;94:20-23.

15. Brown NP, Koretz JF, Bron AJ. The development and maintenance of emmetropia. Eye (Lond). 1999;13(pt 1):83-92.

16. Kasthurirangan S, Markwell EL, Atchison DA, Pope JM. In vivo study of changes in refractive index distribution in the human crystalline lens with age and accommodation. Invest Ophthalmol Vis Sci. 2008;49:2531-2540.

17. Gordon R, Donzis PB. Refractive development of the human eye. Arch Ophthalmol. 1985;103:785-789.

18. Morgan I, Rose K. How genetic is school myopia? Prog Retin Eye Res. 2005;24:1-38.

19. Morgan IG, Rose KA. Myopia and international educational performance. Ophthalmic Physiol Opt. 2013;33:329-338.

20. Kinge B, Midelfart A, Jacobsen G, Rystad J. Biometric changes in the eyes of Norwegian university students-a three-year longitudinal study. Acta Ophthalmol Scand. 1999;77:648-652.

21. Fledelius HC. Adult onset myopia-oculometric features. Acta Ophthalmol Scand. 1995;73:397-401.

22. McBrien NA, Adams DW. A longitudinal investigation of adultonset and adult-progression of myopia in an occupational group. Refractive and biometric findings. Invest Ophthalmol Vis Sci. 1997;38:321-333.

23. Iribarren R, Morgan IG, Nangia V, Jonas JB. Crystalline lens power and refractive error. Invest Ophthalmol Vis Sci. 2012; 53:543-550.

24. Fotouhi A, Hashemi H, Shariati M, et al. Cohort profile: Shahroud Eye Cohort Study. Int J Epidemiol. 2013;42:13001308.

25. Olsen T. On the calculation of power from curvature of the cornea. Br J Ophthalmol. 1986;70:152-154.

26. Chylack LT Jr, Wolfe JK, Singer DM, et al. The Lens Opacities Classification System III. The Longitudinal Study of Cataract Study Group. Arch Ophthalmol. 1993;111:831-836.

27. Bennett AG. A method of determining the equivalent powers of the eye and its crystalline lens without resort to phakometry. Ophthalmic Physiol Opt. 1988;8:53-59.

28. Iribarren G, Iribarren I. Prevalence of myopic shifts in patients seeking cataract surgery. Medicina (B Aires). 2013;73:207212.
29. Asgari S, Hashemi H, Mehravaran S, et al. Corneal refractive power and eccentricity in the 40- to 64-year-old population of Shahroud, Iran. Cornea. 2013;32:25-29.

30. Hashemi H, Khabazkhoob M, Miraftab M, et al. The distribution of axial length, anterior chamber depth, lens thickness, and vitreous chamber depth in an adult population of Shahroud, Iran. BMC Ophthalmol. 2012;12:50.

31. Larsen JS. The sagittal growth of the eye. II. Ultrasonic measurement of the axial diameter of the lens and the anterior segment from birth to puberty. Acta Ophthalmol (Copenh). 1971;49:427-440.

32. Sorkin JD, Muller DC, Andres R. Longitudinal change in the heights of men and women: consequential effects on body mass index. Epidemiol Rev. 1999;21:247-260.

33. Sorkin JD, Muller DC, Andres R. Longitudinal change in height of men and women: implications for interpretation of the body mass index: the Baltimore Longitudinal Study of Aging. Am J Epidemiol. 1999;150:969-977.

34. Seet B, Wong TY, Tan DT, et al. Myopia in Singapore: taking a public health approach. Br J Ophthalmol. 2001;85:521-526.

35. Morgan I, Ohno-Matsui K, Saw S. Myopia. Lancet. 2012;379: 1739-1748.

36. Sorsby A, Leary GA. A longitudinal study of refraction and its components during growth. Spec Rep Ser Med Res Counc ( $G$ B). 1969;309:1-41.

37. Sorsby A, Benjamin B, Sheridan M, Stone J, Leary GA. Refraction and its components during the growth of the eye from the age of three. Memo Med Res Counc. 1961; 301(special):1-67.

38. Ronneburger A, Basarab J, Howland HC. Growth of the cornea from infancy to adolescence. Ophthalmic Physiol Opt. 2006; 26:80-87.

39. Inagaki $\mathrm{Y}$. The rapid change of corneal curvature in the neonatal period and infancy. Arch Ophthalmol. 1986;104: 1026-1027.

40. Gudmundsdottir E, Jonasson F, Jonsson V, Stefansson E, Sasaki $\mathrm{H}$, Sasaki K. "With the rule" astigmatism is not the rule in the elderly. Reykjavik Eye Study: a population based study of refraction and visual acuity in citizens of Reykjavik 50 years and older. Iceland-Japan Co-Working Study Groups. Acta Ophthalmol Scand. 2000;78:642-646.

41. Pesudovs K, Elliott DB. Refractive error changes in cortical, nuclear, and posterior subcapsular cataracts. Br J Ophthalmol. 2003;87:964-967.

42. Brown NAP, Bron AJ. Lens Disorders: A Clinical Manual of Cataract Diagnosis. Oxford: Butterworth-Heinemann; 1996.

43. Duke-Elder S. System of Ophthalmology: Diseases of the Lens and Vitreous: Glaucoma and Hypotony. London: H. Klimpton; 1969.

44. Cole TJ. Secular trends in growth. Proc Nutr Soc. 2000;59: 317-324.

45. Cole TJ. The secular trend in human physical growth: a biological view. Econ Hum Biol. 2003;1:161-168.

46. Haghdoost AA, Mirzazadeh A, Alikhani S. Secular trend of height variations in Iranian population born between 1940 and 1984. Iran J Public Health. 2008;37:1-7.

47. Ayatollahi SMT, Pourahmad S, Shayan Z. Trend in physical growth among children in southern Iran, 1988-2003. Ann Hum Biol. 2006;33:510-514.

48. Ayatollahi SMT, Bagheri Z. New trends in weight-for-height charts of Shirazi school children in relation to the CDC reference data. Iran J Pediatr. 2010;20:407-412.

49. Selovic A, Juresa V, Ivankovic D, Malcic D, Selovic Bobonj G. Relationship between axial length of the emmetropic eye and the age, body height, and body weight of schoolchildren. $A m \mathrm{~J}$ Hum Biol. 2005;17:173-177. 
50. Wong TY, Foster PJ, Johnson GJ, Klein BE, Seah SK. The relationship between ocular dimensions and refraction with adult stature: the Tanjong Pagar Survey. Invest Ophthalmol Vis Sci. 2001;42:1237-1242.

51. Saw SM, Chua WH, Hong CY, et al. Height and its relationship to refraction and biometry parameters in Singapore Chinese children. Invest Ophthalmol Vis Sci. 2002;43:1408-1413.

52. Ojaimi E, Morgan IG, Robaei D, et al. Effect of stature and other anthropometric parameters on eye size and refraction in a population-based study of Australian children. Invest Ophthalmol Vis Sci. 2005;46:4424-4429.

53. Wu HM, Gupta A, Newland HS, Selva D, Aung T, Casson RJ. Association between stature, ocular biometry and refraction in an adult population in rural Myanmar: the Meiktila eye study. Clin Experiment Ophthalmol. 2007;35:834-839.

54. Lee KE, Klein BE, Klein R, Quandt Z, Wong TY. Association of age, stature, and education with ocular dimensions in an older white population. Arch Ophthalmol. 2009;127:88-93.

55. Nangia V, Jonas JB, Matin A, Kulkarni M, Sinha A, Gupta R. Body height and ocular dimensions in the adult population in rural Central India. The Central India Eye and Medical Study. Graefes Arch Clin Exp Ophthalmol. 2010;248:16571666.

56. Blomdahl S. Ultrasonic measurements of the eye in the newborn infant. Acta Ophthalmol (Copenh). 1979;57:10481056.

57. Saw SM, Tong L, Chia KS, et al. The relation between birth size and the results of refractive error and biometry measurements in children. Br J Ophthalmol. 2004;88:538-542.

58. Ojaimi E, Robaei D, Rochtchina E, Rose KA, Morgan IG, Mitchell P. Impact of birth parameters on eye size in a population-based study of 6-year-old Australian children. $A m \mathrm{~J}$ Ophthalmol. 2005;140:535-537.

59. Sun C, Ponsonby AL, Brown SA, et al. Associations of birth weight with ocular biometry, refraction, and glaucomatous endophenotypes: the Australian Twins Eye Study. Am J Ophthalmol. 2010;150:909-916.

60. Teikari JM. Myopia and stature. Acta Ophthalmol (Copenh). 1987;65:673-676.

61. Jung SK, Lee JH, Kakizaki H, Jee D. Prevalence of myopia and its association with body stature and educational level in 19year-old male conscripts in Seoul, South Korea. Invest Ophthalmol Vis Sci. 2012;53:5579-5583.

62. Lee JH, Jee D, Kwon JW, Lee WK. Prevalence and risk factors for myopia in a rural Korean population. Invest Ophthalmol Vis Sci. 2013;54:5466-5470.

63. Sharma A, Congdon N, Gao Y, et al. Height, stunting, and refractive error among rural Chinese schoolchildren: the See Well to Learn Well project. Am J Ophthalmol. 2010;149:347353, e341.

64. Dirani M, Islam A, Baird PN. Body stature and myopia-The Genes in Myopia (GEM) twin study. Ophthalmic Epidemiol. 2008; 15:135-139.

65. Rosner M, Laor A, Belkin M. Myopia and stature: findings in a population of 106,926 males. Eur J Ophthalmol. 1995;5:1-6.

66. Pokharel GP, Negrel AD, Munoz SR, Ellwein LB. Refractive Error Study in Children: results from Mechi Zone, Nepal. Am J Ophthalmol. 2000;129:436-444.

67. Augusteyn RC. On the growth and internal structure of the human lens. Exp Eye Res. 2010;90:643-654.

68. Lovicu FJ, McAvoy JW. Growth factor regulation of lens development. Dev Biol. 2005;280:1-14. 